\title{
Intestinal development of bovine foetuses during gestation is affected by foetal sex and maternal nutrition
}

\author{
T. R. S. Gionbelli ${ }^{1}$, P. P. Rotta ${ }^{2}$, C. M. Veloso ${ }^{2}$, S. C. Valadares Filho ${ }^{2}$, B. C. Carvalho ${ }^{3}$, M. I. Marcondes ${ }^{2}$, \\ M. F. L. Ferreira ${ }^{2}$, J. V. F. Souza' ${ }^{2}$, J. S. A. A. Santos ${ }^{2}$, L. C. Lacerda ${ }^{2}$, M. S. Duarte ${ }^{2}$ and M. P. Gionbelli ${ }^{1}$ \\ 1 Department of Animal Sciences, Universidade Federal de Lavras, Lavras, Brazil \\ 2 Department of Animal Sciences, Universidade Federal de Viçosa, Viçosa, Brazil, and \\ 3 Embrapa Dairy Cattle, Brazilian Corporation of Agricultural Research, Coronel Pacheco, Brazil
}

\section{Summary}

We aimed to evaluate the effects of maternal nutrition (MN) and foetal sex on the intestinal development of bovine foetuses throughout different days of gestation (DG). Forty-four multiparous, dry Holstein $\times$ Gyr cows with average initial body weight of $480 \pm 10 \mathrm{~kg}$ were fed the same diet of either restricted feeding at $1.15 \%$ of body weight (CO, $n=24$ ) or fed ad libitum (overnourished, ON, $n=20)$. Six cows from CO group and five cows from ON group were slaughtered at 139, 199, 241 and 268 DG, and foetuses were necropsied to evaluate the intestinal development. The mass, length and density of foetal intestines were not affected by $M N(p \geq 0.260)$. An interaction between MN and DG was observed for the villi length of jejunum $(p=0.006)$ and ileum $(p<0.001)$. Villi length of jejunum and ileum was higher $(p<0.10)$ in foetuses from ON-fed cows than in foetuses from CO-fed cows at 139 DG. However, at 199 DG, the villi length of jejunum and ileum of foetuses from CO-fed cows was higher than in foetuses from ON-fed cows. Despite these differences, MN did not affect the villi length of jejunum and ileum at $268 \mathrm{DG}(\mathrm{p}>0.10)$. Female foetuses had greater small intestine mass $(\mathrm{p}=0.093)$, large intestine mass $(p=0.022)$, small intestine mass in proportion to body mass $(p=0.017)$ and large intestine mass in proportion to body mass $(\mathrm{p}<0.001)$ than male foetuses. Female foetuses had also longer small intestine $(p=0.077)$ and greater small intestine density $(p=0.021)$ and villi length of jejunum $(p=0.001)$ and ileum $(\mathrm{p}=0.010)$ than males. We conclude that $\mathrm{MN}$ affects the pathway for the development of foetal villi length throughout the gestation in bovine foetuses without changing the final villi length. Female foetuses had higher intestinal mass, density and villi length than males during the foetal phase in bovines.

Keywords absorption, feeding level, foetal programming, intestinal morphology, small intestine, sex-biased, villi length, zebu

Correspondence Prof. M. P. Gionbelli, Departamento de Zootecnia, Universidade Federal de Lavras, Campus Universitario UFLA, $37200-000$ Lavras, MG, Brazil. Tel: +55 35 38294518; Fax: +55 35 38291230; E-mail: mateus.pg@dzo.ufla.br

Received: 20 February 2016; accepted: 13 June 2016

\section{Introduction}

In bovines, the intact absorption of macromolecules as immunoglobulin through the intestine wall occurs during the first hours of post-natal life. Thus, a proper intestine development during intrauterine stage is crucial to decrease morbidity and mortality. As the main site of nutrient absorption, intestinal development changes during foetal stage have been shown to permanently affect the efficiency of nutrient usage (Trahair et al., 1997; Godfrey and Barker, 2000; Wu et al., 2006; Wang et al., 2008).

Maternal nutritional restriction from conception to mid-gestation may decrease foetal intestinal mucosa diameter and area in sheep (Trahair et al., 1997).
However, foetuses from cows submitted to nutritional restriction may present greater vascularization and cellular proliferation at the jejunum, and higher relative size of intestine and villi length (Duarte et al., 2013). Moreover, it has been reported that lambs from ewes submitted to nutritional restriction had better immunoglobulin absorption efficiency during the first hours after birth, while lambs from overnourished sheep had reduced immunoglobulin absorption efficiency (Hammer et al., 2011). In many of these cases, the foetal intestinal development changes were suggested as adjustments due to a lower or higher maternal ability to produce colostrum according to the feeding level during pregnancy (Swanson et al., 2008; Hammer et al., 2011; Duarte et al., 2013). 
Information on the direct effects of maternal feeding plan on the foetal intestinal development independent of colostrum production is lacking. None of the previous studies in cattle (Meyer et al., 2010; Duarte et al., 2013) used dairy cows. Such animals are often subject to different nutritional plans during gestation according to previous lactation and dry periods (Holtenius et al., 2003; Odensten et al., 2005; March et al., 2014) and even then producing significant amounts of colostrum in the post-natal period (Kessler et al., 2013; Garcia et al., 2014).

In addition to the limited number of studies regarding dietary effects on gastrointestinal development of bovine foetuses, to our knowledge there are no previous studies highlighting foetal sex (FS) differences regarding intrauterine intestinal development. Therefore, we hypothesized that different maternal feeding levels may affect the foetal intestine development of high-genetic-merit dairy cattle. From an investigative form, we proposed the FS inclusion as one of the factors involved on an intrauterine development of cattle intestine. Therefore, this study aimed to evaluate maternal feeding level and FS effects on intestinal development of cattle foetuses along different gestation stages.

\section{Materials and methods}

This study was performed at Universidade Federal de Viçosa (Viçosa, MG, Brazil), following the standard procedures of animal welfare and handling according to Animal Use Ethics Committee from Universidade Federal de Viçosa.

Forty-four Holstein $\times$ Gyr cows, non-lactating, multiparous, with an average initial body weight of $480 \pm 10.1 \mathrm{~kg}$ and an initial age of $5 \pm 0.5$ years old were confirmed to be pregnant after a fixed-time artificial insemination protocol using semen from a single Holstein bull. Reproductive protocol procedures used for cows in this work were previously described (Rotta et al., 2015). The day of artificial insemination was considered as the day zero of gestation.

On day 40 of gestation, cows were individually housed in $15 \mathrm{~m}^{2}$ pens, of which $4 \mathrm{~m}^{2}$ was covered, equipped with concrete feed bunks and an automatic water system. On day 60 of gestation, foetal sexing was performed by transrectal ultrasound (Aloka 500 with a 5-MHz linear probe; Aloka, Wallingford, CT, USA).

The feed intake control was performed from day 60 of gestation until cows reached the designated slaughter time. After foetal sexing, cows were randomly assigned in two groups by different feeding levels: control group ( $\mathrm{CO}, n=24$ ) with restricted feeding at $1.15 \%$ of body weight based on dry matter or overnourished (ON, $n=20)$ with ad libitum feeding. Both groups received the same experimental diet, but differed in feed intake level. Restricted feeding level (CO) was planned for the gestation maintenance with a minimal body tissue gain (Gionbelli et al., 2015), whereas the ad libitum feeding treatment (ON) was planned to allow a body reserve deposition.

Every 28 days cows were weighed in the morning to monitor the body weight, so the dry matter intake of treatment $\mathrm{CO}$ could be adjusted to maintain the feed restriction during the entire gestational period.

Experimental diets consisted of $11.1 \%$ of crude protein and $67.4 \%$ of total digestible nutrients, and composed of $93 \%$ of corn silage, $5 \%$ of cotton meal, $0.9 \%$ of urea, $0.1 \%$ of ammonium sulphate and $1 \%$ of mineral mix. Mineral mix was formulated to meet the maintenance and gestation requirements according to Dairy Cattle NRC System (NRC 2001). Cows were fed twice daily, with $60 \%$ of the diet offered in the morning (07:00 hours) and $40 \%$ in the afternoon (15:00 hours). To allow ad libitum feed access on ON treatment, feed delivery was adjusted to have orts of $5 \%$ from the offered amount. All cows had ad libitum access to water during the entire experiment.

To evaluate the gestation stage effect, 44 cows were randomly assigned into four groups $(n=11$ in each group, being six $\mathrm{CO}$ and five $\mathrm{ON}$ ) slaughtered at 136 , 199, 241 and 268 days of gestation (DG) respectively. Randomization was repeated until a sufficient number of male and female foetuses were reached in each subgroup (nutritional treatment in gestation stage). The four gestation stages in which pregnant cows were slaughtered corresponded to $50 \%, 70 \%, 85 \%$ and $95 \%$, respectively, of the average gestation stage (284 days) for Holstein $\times$ Gyr cows (Mellado et al., 2011 ) and $18 \%, 31 \%, 73 \%$ and $96 \%$ of the total growing gravid uterus (Gionbelli et al., 2015).

Slaughtering procedures followed the Sanitary and Industrial Inspection Regulation for Animal Origin Products from Ministry of Agriculture, Livestock and Supply (Brasil 1997). Cows were submitted to 16-h fasting prior to slaughter with free access to water. Slaughter was performed using captive bolt stunning followed by jugular vein exsanguination. Euthanasia of foetuses followed the American Veterinary Medical Association Guidelines (AVMA 2013).

After the exsanguination, gravid uterus was immediately collected, and foetuses were removed. Foetus 
dissection and intestine isolation were performed similar to Meyer et al. (2010). Therefore, foetuses were dissected, and the gastrointestinal tract was carefully separated from offal, fat and digests. Small intestine was isolated from pyloric valve. Large intestine was separated from the small intestine by the caecum junction (ileocecal valve), with both separately measured and weighed after a careful removal of contents. Afterwards, small intestine was divided into duodenum, jejunum and ileum similarly described by Soto-Navarro et al. (2004) as follows: duodenum was identified as the segment from pylorus up to a point directly adjacent to the gastrosplenic vein entrance into the mesenteric vein. Jejunum was identified as the segment formed from duodenum caudal part up to jejunum and ileum junction. This junction was determined by measuring $15 \mathrm{~cm}$ after mesenteric vein from the convergence of mesenteric and ileocecal veins to the mesenteric arcade. From this point, a $100 \mathrm{~cm}$ measurement was realized caudally down to intestine, identified as the jejunum terminal portion and beginning of ileum. Intestine ileal portion was considered from the end of jejunum up to ileocecal junction.

Jejunum and ileum samples with $4 \mathrm{~cm}$ size were gently collected from the middle portion of each intestinal section and fixed with 10\% (weight/volume) formalin in phosphate buffer ( $\mathrm{pH}$ 7.4) and then embedded using the HistoResin Mounting Kit (Leica ${ }^{\circledR}$, Heidelberg, BW, Germany). Fragments of small intestine were carefully embedded to allow the presence of a great number of villi longitudinally oriented in each section. Sections were cut at $3 \mu \mathrm{m}$ using glass blade microtome (Reichert Jung, Mod 1140/Autocut, Vienna, Austria). One in every 10 sections obtained in series was stretched in distilled water, placed on a histological slide, dried in hot plate at $60{ }^{\circ} \mathrm{C}$ and then stained with toluidine blue sodium borate and subsequently observed under light microscope. For each small intestine fragment (jejunum and ileum) from each animal, only intact villi, with an evident lamina propria at both the base and top, were selected for the villi length measurement.

Photomicrographs were taken with a CMOS digital camera (Biocam GmbH ${ }^{\circledR}$, Regensburg, Germany) coupled to an Olympus BX50 light microscope (Center Valley, PA, USA). Ten fields and a maximum of ten villi per field were randomly selected to measure the villi length. Images were analysed using the Image ${ }^{\circledR}$ software (U. S. National Institutes of Health, Bethesda, MD, USA), and a total of 70 villi per section from each animal ( 7 villi per field $\times 10$ fields in average) were measured. Measurements of curved villi were performed by using the segmented line tool of Image $^{\circledR}$ software.

Data were analysed through a model, including the fixed effects of maternal nutrition $(\mathrm{MN}), \mathrm{FS}$, gestational period and their interaction, using a $2 \times 2 \times 4$ factorial design (two maternal feeding levels, two genders and four gestation stages) in a completely randomized design. Each foetus was considered as one experimental unit once the treatment was individually applied to their dams. The statistical model is described below:

$$
\begin{aligned}
Y_{i j k l}= & \mu+N_{i}+G_{j}+T_{k}+(N \times G)_{i j}+(N \times T)_{i k} \\
& +(G \times T)_{j k}+(N \times G \times T)_{i j k}+e_{i j k l}
\end{aligned}
$$

where $N_{i}$ is the $i$ th level of the MN-fixed effect, $G_{j}$ is the $j$ th level of the FS-fixed effect, $T_{k}$ is the $k$ th level of the gestation stage-fixed effect and $e_{i j k}$ the random error associated with $Y_{i j k}$.

The Shapiro-Wilk test (Shapiro and Wilk, 1965) at $\alpha=0.10$ was performed to test the data normality for all analysed variables before the analyses of variance. Least-square means were estimated for all effects and compared using Tukey's method at $\alpha=0.10$. All statistical procedures were performed using the MIXED procedure from SAS 9.2 (Statistical Analysis System Institute, Cary, NC, USA).

\section{Results}

From 44 pregnant cows used in this experiment, one had twin pregnancy $(2.3 \%)$ and two aborted $(4.5 \%)$. Therefore, the presented results correspond to data from 41 simple and healthy gestations.

The ON-fed cows had greater slaughter weight $(\mathrm{p}<0.001)$ than CO-fed cows (Table 1$)$, showing the efficiency of nutritional treatment application. The average feed intake for CO-fed cows was $6.38 \pm 0.32 \mathrm{~kg} /$ day, while the average feed intake observed for ON-fed cows was $11.24 \pm 0.37 \mathrm{~kg} /$ day (Rotta et al., 2015). The final body weight did not differ between pregnant cows of male and female foetuses $(p=0.976)$. No interaction between nutritional treatments, FS and gestation stage was observed for slaughter weight of the cows ( $p \geq 0.557)$.

Foetal weight (Table 1) was affected by gestation stage $(p<0.001)$ and was not affected by FS ( $p=$ $0.518)$, maternal nutritional treatment $(p=0.330)$ or the interactions between maternal nutritional treatment, FS and gestational period ( $p \geq 0.367)$. Therefore, in this study variables related to the intestinal development within each gestation stage were not affected by foetal size. 
Foetal intestinal mass, length and density (Table 2) were not affected by $M N(p \geq 0.260)$ nor by the interaction between the maternal nutritional treatment, foetal gender and gestation stage $(p \geq 0.113)$. Female foetuses had greater mass for both small $(\mathrm{p}=0.093)$ and large $(\mathrm{p}=0.022)$ portions than male foetuses. Total mass of intestine and its portions increased during gestation $(p<0.001)$. However, no significant increase in the small intestine $(p=0.289)$ relative to body mass $(\mathrm{g} / \mathrm{kg})$ during gestation was observed, whereas foetal large intestine grew relatively higher than foetal body at 199 DG $(p=0.01)$. Females also had greater small $(p=0.017)$, large $(p=0.001)$ and total $(p=0.003)$ intestinal mass relative to body mass $(\mathrm{g} / \mathrm{kg})$ than male foetuses. The average difference between FSs was 18\% for total mass and 13\% for mass relative to body mass.

Although intestinal mass differed between sexes (Table 2), female and male foetuses had no difference in length $(\mathrm{cm})$ of small intestine $(\mathrm{p}=0.753)$ and total intestine $(\mathrm{p}=0.604)$. However, the large intestine was $9 \%$ longer in female than in male foetuses $(p=0.077)$. The foetal total intestine length and its portions increased during gestation $(p<0.001)$ with the greatest increase occurring between 139 and 199 days $(130 \%)$. However, there was no significant increase in foetal total intestine length and its portions between 241 and 268 DG $(\mathrm{p}>0.10)$.

The density $(\mathrm{g} / \mathrm{cm})$ of small $(\mathrm{p}=0.021)$ and total $(p=0.009)$ intestine was greater in female than in male foetuses (Table 2). However, no difference was observed between genders for large intestine density $(\mathrm{p}=0.173)$. In both intestinal portions and also in total intestine, a density increase was observed according to the gestation stage $(\mathrm{p}<0.001)$ such that the foetal intestine at the end of gestation (269 days) was six times denser than in mid-gestation (139 days).

Differences along the intestinal villi development during gestation due the maternal dietary treatment were observed (Table 3). An interaction between MN and gestation stage for the jejunum $(p=0.006)$ and ileum $(\mathrm{p}<0.001)$ villi length $(\mu \mathrm{m})$ was observed. At mid-gestation (139 days), foetuses from ON cows had higher intestinal villi length of jejunum and ileum $(p<0.1)$ than foetuses from CO cows (Fig. 1). Conversely, at 199 DG foetuses from CO cows had higher intestinal villi length of jejunum and ileum than foetuses from ON cows. Higher villi length in CO foetuses of 241 gestation days was observed at the ileum $(p<0.1)$, but not at the jejunum $(p>0.1)$. However, at 268 DG, ileum and jejunum intestinal villi length did not differ $(p>0.1)$ between CO and ON foetuses. The overall effect of MN was not significant 


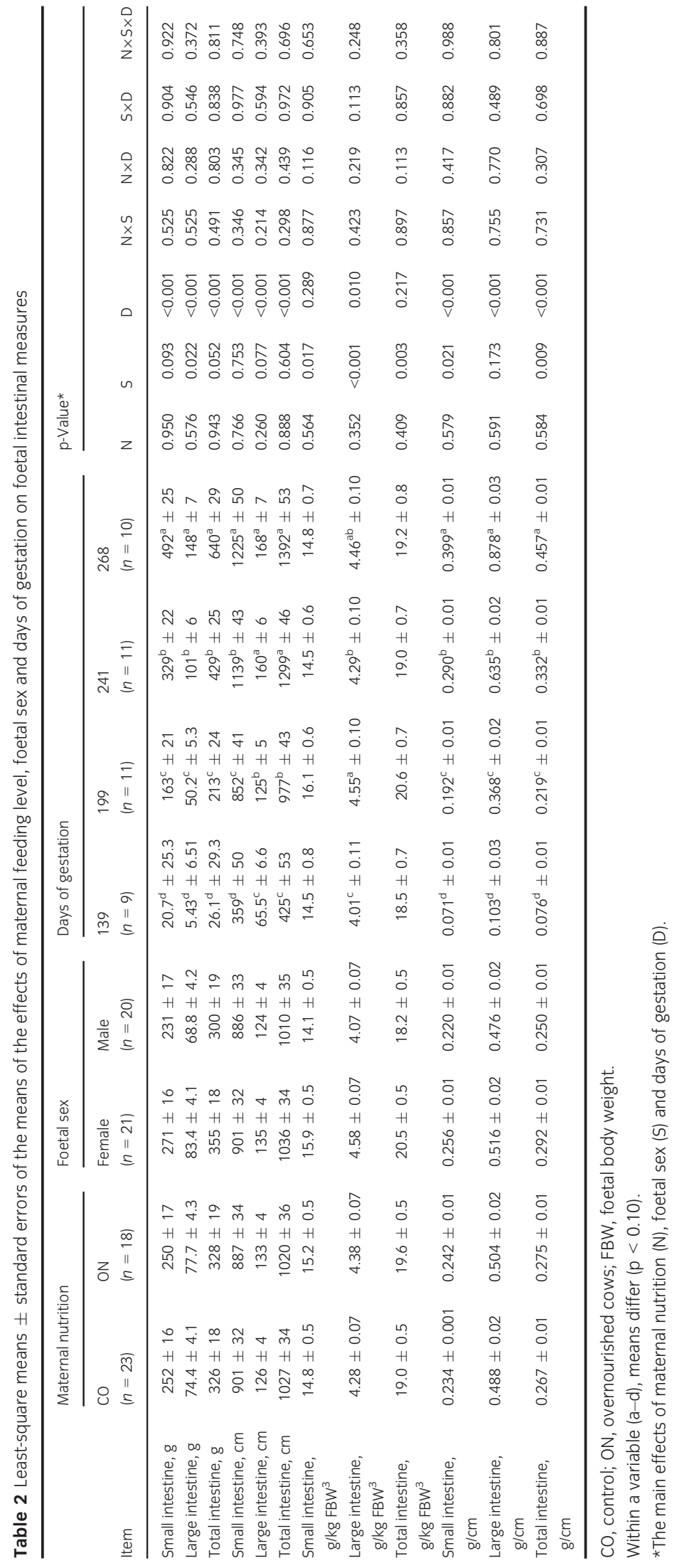


$(\mathrm{p}=0.599$ and $\mathrm{p}=0.484$ for jejunum and ileum respectively), but the verified interaction indicates an early development of ON cows foetal villi length, although when approaching the end of pregnancy a compensatory effect of villi lengthening occurred in foetuses from CO cows.

As for intestinal mass and density, female foetuses also showed higher villi length in the jejunum $(p=0.001)$ and ileum $(p=0.01)$ compared to male foetuses (Table 3). In general, villi length of jejunum and ileum was $11 \%$ and $9 \%$ higher, respectively, in females than in males, with no interaction between gender and $\mathrm{MN}(\mathrm{p} \geq 0.381)$ and gestational period $(p \geq 0.128)$ or between gender and MN and gestation stage $(p \geq 0.560)$.

\section{Discussion}

To our knowledge, this is the first work evaluating $\mathrm{MN}$ and FS effects on the foetal intestinal development in cattle with a great potential to produce milk at maturity and, consequently, to produce a great amount of colostrum at post-partum.

Marginal effects of maternal feeding levels above maintenance during gestation were observed on the foetal intestinal development in this study. Most of the studies have reported changes in the normal development of ruminant foetal intestine due to the possible adaptations of lower colostrum availability during the post-partum period. Swanson et al. (2008) observed lower colostrum production but with similar immunoglobulin concentration in sheep that received $60 \%$ or $140 \%$ of nutritional requirements compared with those that received $100 \%$ of nutritional requirement during gestation. However, immunoglobulin absorption efficiency of lambs from sheep that were restricted was better than the other treatments (Hammer et al., 2011). The hypothesis of intrauterine intestinal developmental adaptations as a response to a lower $\mathrm{MN}$ intake during cattle gestation has been reported (Meyer et al., 2010; Duarte et al., 2013). However, in the present work the maternal nutritional levels did not cause weight loss, whereas $\mathrm{CO}$ and ON cows had average body weight gain of 0.11 and $0.94 \mathrm{~kg} /$ day respectively (Rotta et al., 2015). When pregnant ruminant females were fed over the maintenance level compared to ones fed close to the maintenance level, there were negative impacts on the foetal intestinal development in cattle (Duarte et al., 2013) and in sheep (Yanusova et al., 2013). However, during the post-natal period lambs from dams fed with $140 \%$ of the nutritional requirements during pregnancy had higher intestinal

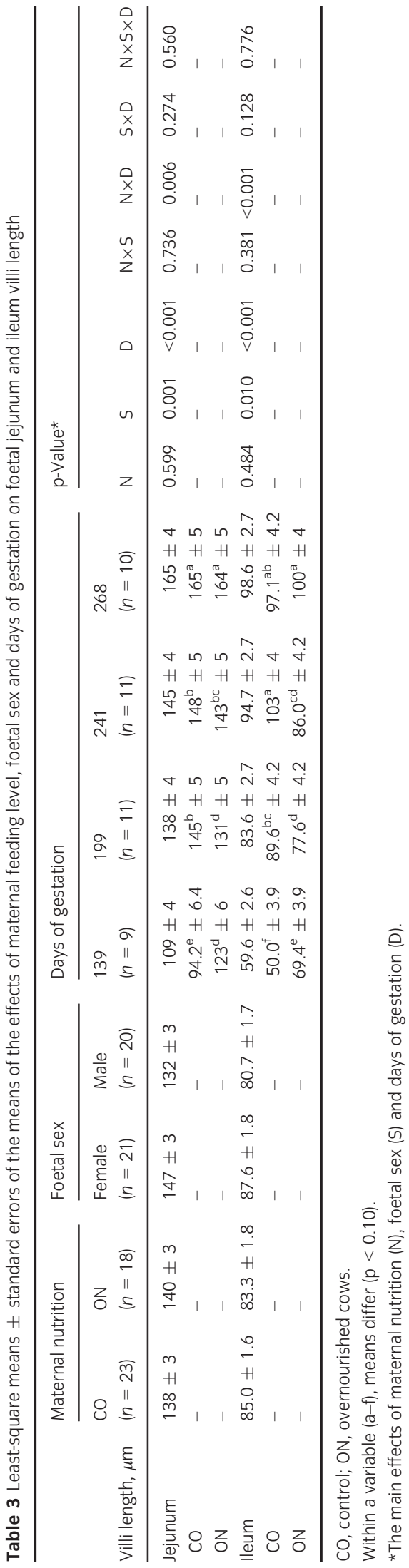


Fig. 1 Differences in foetuses' ileum in function of maternal nutrition at mid-gestation. Representative photomicrograph $(10 x)$ in the same sample range of male foetuses' ileum at 139 days of gestation, from CO cow (left) to ON cow (right), showing differences in villi length. [Colour figure can be viewed at wileyonlinelibrary.com]
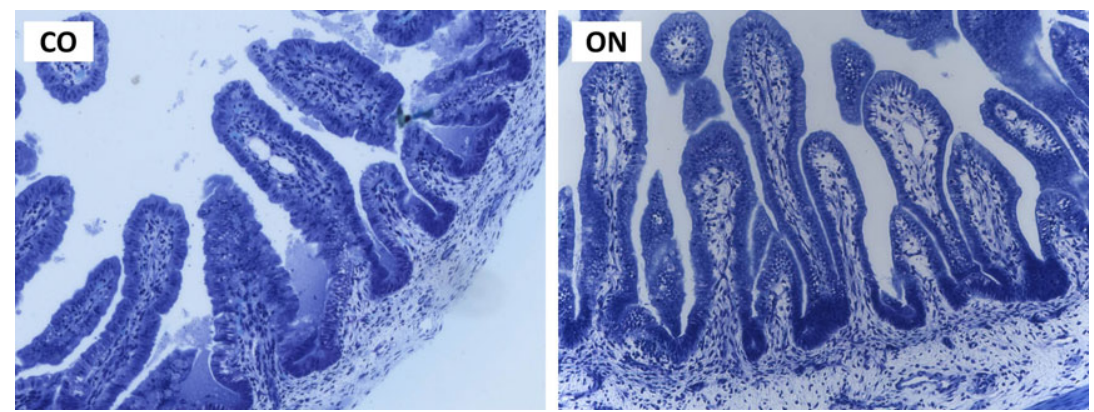

activity of maltase compared to those from dams fed close to maintenance level (Yanusova et al., 2013), which seems to be a compensatory response to the negative effects of excessive maternal feeding level on the foetal intestinal development. Such compensatory effects are similar to those observed in offspring from female ruminants that had feed restriction during gestation (Meyer et al., 2010; Hammer et al., 2011; Yanusova et al., 2013).

However, it should be noted that foetuses from ON cows in the current study had earlier villi development than foetuses from $\mathrm{CO}$ cows during pregnancy (Table 3, Fig. 1). It is possible that such effect has occurred due to the increased nutrient supply to foetuses from ON cows during the mid-gestation, in which the internal organs' growth rates are larger (Gionbelli, 2013). Nevertheless, these differences were not observed in the present study in foetuses from cows slaughtered in the last third of gestation (241 and 268 days), suggesting that there is no difference in the offspring's intestinal villi length after birth due to the maternal feeding level during gestation.

In this study, the lack of MN effect on the final result of foetal intestine development may be associated with the increased milking production potential in the post-natal period, because none of the previous studies used high-genetic-merit dairy cows as an animal model. In cattle, especially in milk production specialized breeds, studies involving MN effects during gestation or pre-partum supplementation on weight at birth, colostrum production and immunoglobulin absorption have received little attention (Garcia et al., 2014). Thus, from the observed results in this study, we hypothesized that the MN effects on the offspring intestinal development are significant only when species or breeds do not have high milk production cows (lower colostrum production) or when restricted intrauterine nutrition occurs drastically (Trahair et al., 1997).

It is important to note that all effects observed in this study occurred with no difference in foetal weight between the maternal feed treatments and FS during gestation (Table 1). Thus, similar foetal or the afterbirth weight might mask important changes that occurred in the normal physiological development during gestation, caused by distinct events.

A new evidenced fact from this study is the greater foetal intestinal development in females compared to males during foetal stage. Intestinal mass, small intestine mass, large intestine mass, intestinal mass relative to body mass for the small intestine, large and total intestine, small intestine length, small intestine and total intestine density (Table 2) and villi length in the jejunum and ileum (Table 3 ) were greater in female than in male foetuses, even with no difference in foetal weight (Table 1). Nevertheless, lactational programming as a function of FS during gestation in dairy cows has been recently demonstrated (Hinde et al., 2014) using a database of 2.39 million lactations of Holstein cows. Hinde et al. (2014) observed that cows pregnant with a female at first calving had a $445 \mathrm{~kg}$ increase in milk production over the first two lactations, compared to cows pregnant with a male, supporting a mammary function programing by the foetuses in utero.

The adaptive maternal resource allocation favouring one of the genders in mammals has been an objective of studies since the 1970s (Trivers and Willard, 1973; Clark, 1978). There are several mammal species in which maternal resources are differently allocated to one of the two genders, and the genetic and environmental factors that triggered such adaptive evolution of maternal favouring of one of the two genders are changeable between species (Smith, 1980; Hinde et al., 2014). The best accepted hypothesis and further investigated on this subject is the Trivers-Willard hypothesis (Trivers and Willard, 1973), which suggests that females, depending on the physiological stage, develop within the species to allocate its resources preferentially to the gender whose survival produces the best return on investment for the species. However, the causes of mammary gland 
programming for the higher milk production when cows are gestating females remain unclear (Hinde et al., 2014). This may be related to a higher intestinal development during the pre-natal phase in females and Trivers-Willard hypothesis (Trivers and Willard, 1973). In the milk production specialized cattle breeds, post-natal effect of a higher developed intestine or increased maternal milk production have not been reported and are difficult to study because usually the offspring are separated from the mother afterbirth and receive artificial feeding. Even in beef cattle, in which the offspring stay with the cow, only marginal effects on the milk production variations due to the offspring gender are observed (Christian et al., 1965; Rutledge et al., 1971; Minick et al., 2001). However, it is noteworthy that normally, in contrast to data suggesting increased nutrient utilization in females, male calves normally are faster growing than females during nursing.

A possible hypothesis for the favoured intestinal development and larger milk production when generating females may be related to the difference in conception rates in cows pregnant with males vs. females. Natural conception rates of males are slightly larger than females, varying between $50 \%$ and $54 \%$ in males against $46 \%$ and $50 \%$ in females (Foote, 1977; Del Río et al., 2007). As bovines are polygamous species, in nature fewer sires would be required. Thus, evolution of maternal resources allocation and intrauterine development to favour post-natal female survival (more developed intestine at birth, larger immune load, higher maternal milk production) would be directed to favour females, as evolutionary compensation for the difficulty to conceive a higher proportion of females.

However, despite the assumptions mentioned in the present work, the causes and/or consequences of gender effect on the foetal intestinal development still remain inconclusive. Nonetheless, it is assumed that enhanced female intestinal development may be correlated with the milk production later in life.

\section{Conclusions}

Maternal nutritional levels above maintenance during gestation affect the course of intestinal villi development throughout gestation in foetuses from Holstein x Gyr cows. However, final size of the villi is not affected. Females have increased intestinal mass, intestinal density and villi size compared to males during the foetal stage.

\section{Acknowledgements}

Authors would like to thank FAPEMIG - Fundação do Amparo à Pesquisa de Minas Gerais (Grant: APQ02111-13) for the financial support to this study.

\section{Conflict of interest}

No competing financial, personal or professional interests have influenced writing of this paper. This manuscript has not been submitted anywhere else for possible publication.

\section{Authors' contributions}

TRSG and MPG wrote the majority of this paper with input from each listed author. TRSG, PPR, CMV, SCVF and MIM planned and outlined the experiment. CMV, SCVF, BCC and MIM revised the manuscript critically for important intellectual content. Statistical analyses were conducted by MPG. Experimental work was conducted by TRSG, PPR, BCC, MFLF, JVFS, JSAAS and LCL. Analysis of results and derivation of conclusions was conducted by TRSG, MSD and MPG.

\section{References}

AVMA, 2013: Guidelines for the Euthanasia of Animals: 2013 Edition. American Veterinary Medical Association, Schaumburg, IL, USA.

Brasil, 1997: Regulamento da Inspeção Industrial e Sanitária de Produtos de Origem Animal [Regulation of Industrial and Sanitary Inspection of Animal Products]. Ministério da Agricultura Pecuária e Abastecimento, Brasília, DF, Brazil (In Portuguese).

Christian, L.; Hauser, E.; Chapman, A., 1965: Association of preweaning and postweaning traits with weaning weight in cattle. Journal of Animal Science 24, 652-659.

Clark, A. B., 1978: Sex ratio and local resource competition in a prosimian primate. Science 201, 163-165.

Del Río, N. S.; Stewart, S.; Rapnicki, P.; Chang, Y.; Fricke, P., 2007: An observational analysis of twin births, calf sex ratio, and calf mortality in Holstein dairy cattle. Journal of Dairy Science $\mathbf{9 0}$, 1255-1264.

Duarte, M. S.; Gionbelli, M. P.; Paulino, P. V. R.; Serão, N. V. L.; Martins, T. S.; Tótaro, P. I. S.; Neves, C. A.; Valadares
Filho, S. C.; Dodson, M. V.; Zhu, M.; Du, M., 2013: Effects of maternal nutrition on development of gastrointestinal tract of bovine fetus at different stages of gestation. Livestock Science 153, 60-65.

Foote, R., 1977: Sex ratios in dairy cattle under various conditions. Theriogenology 8, 349-356.

Garcia, M.; Greco, L. F.; Favoreto, M. G.; Marsola, R. S.; Martins, L. T.; Bisinotto, R. S.; Shin, J. H.; Lock, A. L.; Block, E.; Thatcher, W. W.; Santos, J. E. P.; Staples, C. R., 2014: Effect of supplementing fat to pregnant nonlactating cows on colostral fatty acid profile and passive 
immunity of the newborn calf. Journal of Dairy Science 97, 392-405.

Gionbelli, M. P., 2013: Nutrient Requirements and Quantitative Aspects of Growth, Development and Digestion of Pregnant and Non-Pregnant Nellore Cows. Departamento de Zootecnia, Universidade Federal de Viçosa, Viçosa, p.198.

Gionbelli, M. P.; Duarte, M. S.; Valadares Filho, S. C.; Detmann, E.; Chizzotti, M. L.; Rodrigues, F. C.; Zanetti, D.; Gionbelli, T. R. S.; Machado, M. G., 2015: Achieving body weight adjustments for feeding status and pregnant or nonpregnant condition in beef cows. PLoS One 9, el 15724.

Godfrey, K. M.; Barker, D. J., 2000: Fetal nutrition and adult disease. The American Journal of Clinical Nutrition $\mathbf{7 1}$, 1344s-1352s.

Hammer, C. J.; Thorson, J. F.; Meyer, A. M.; Redmer, D. A.; Luther, J. S.; Neville, T. L.; Reed, J. J.; Reynolds, L. P.; Caton, J. S.; Vonnahme, K. A., 2011: Effects of maternal selenium supply and plane of nutrition during gestation on passive transfer of immunity and health in neonatal lambs. Journal of Animal Science 89, 3690-3698.

Hinde, K.; Carpenter, A. J.; Clay, J. S.; Bradford, B. J., 2014: Holsteins favor heifers, not bulls: biased milk production programmed during pregnancy as a function of fetal sex. PLoS One $\mathbf{9}$, e86169.

Holtenius, K.; Agenäs, S.; Delavaud, C.; Chilliard, Y., 2003: Effects of feeding intensity during the dry period. 2. Metabolic and hormonal responses. Journal of Dairy Science 86, 883-891.

Kessler, E. C.; Bruckmaier, R. M.; Gross, J. J., 2013: Milk production during the colostral period is not related to the later lactational performance in dairy cows. Journal of Dairy Science 97, 2186-2192.

March, M. D.; Haskell, M. J.; Chagunda, M. G. G.; Langford, F. M.; Roberts, D. J.,
2014: Current trends in British dairy management regimens. Journal of Dairy Science 97, 7985-7994.

Mellado, M.; Coronel, F.; Estrada, A.; Ríos, F. G., 2011: Lactation performance of Holstein and Holstein x Gyr cattle under intensive condition in a subtropical environment. Tropical and Subtropical Agroecosystems 14, 927-931.

Meyer, A. M.; Reed, J. J.; Vonnahme, K. A.; Soto-Navarro, S. A.; Reynolds, L. P.; Ford, S. P.; Hess, B. W.; Caton, J. S., 2010: Effects of stage of gestation and nutrient restriction during early to midgestation on maternal and fetal visceral organ mass and indices of jejunal growth and vascularity in beef cows. Journal of Animal Science 88, 2410-2424.

Minick, J.; Buchanan, D.; Rupert, S., 2001: Milk production of crossbred daughters of high-and low-milk EPD Angus and Hereford bulls. Journal of Animal Science 79, 1386-1393.

NRC, 2001: Nutrient Requirements of Dairy Cattle, 7th edn. National Academy Press, Washington, DC, USA.

Odensten, M. O.; Chilliard, Y.; Holtenius, K., 2005: Effects of two different feeding strategies during dry-off on metabolism in high-yielding dairy cows. Journal of Dairy Science 88, 2072-2082.

Rotta, P. P.; Valadares Filho, S. C.; Gionbelli, T. R. S.; Costa e Silva, L. F.; Engle, T. E.; Marcondes, M. I.; Machado, F. S.; Villadiego, F. A. C.; Silva, L. H. R., 2015 : Effects of day of gestation and feeding regimen in Holstein x Gyr cows: I. Apparent total tract digestibility, nitrogen balance, and fat deposition. Journal of Dairy Science. 98, 3197-3210.

Rutledge, J.; Robison, O.; Ahlschwede, W.; Legates, J., 1971: Milk yield and its influence on 205-day weight of beef calves. Journal of Animal Science 33, 563-567.

Shapiro, S. S.; Wilk, M. B., 1965: An analysis of variance test for normality (complete samples). Biometrika 52, 591-611.
Smith, J. M., 1980: A new theory of sexual investment. Behavioral Ecology and Sociobiology 7, 247-251.

Soto-Navarro, S. A.; Lawler, T. L.; Taylor, J. B.; Reynolds, L. P.; Reed, J. J.; Finley, J. W.; Caton, J. S., 2004: Effect of highselenium wheat on visceral organ mass and intestinal cellularity and vascularity in finishing beef steers. Journal of Animal Science 82, 1788-1793.

Swanson, T. J.; Hammer, C. J.; Luther, J. S.; Carlson, D. B.; Taylor, J. B.; Redmer, D. A.; Neville, T. L.; Reed, J. J.; Reynolds, L. P.; Caton, J. S.; Vonnahme, K. A., 2008: Effects of gestational plane of nutrition and selenium supplementation on mammary development and colostrum quality in pregnant ewe lambs. Journal of Animal Science 86, 2415-2423.

Trahair, J. F.; DeBarro, T. M.; Robinson, J. S.; Owens, J. A., 1997: Restriction of nutrition in utero selectively inhibits gastrointestinal growth in fetal sheep. The Journal of Nutrition 127, 637-641.

Trivers, R. L.; Willard, D. E., 1973: Natural selection of parental ability to vary the sex ratio of offspring. Science 179, 90-92.

Wang, J.; Chen, L.; Li, D.; Yin, Y.; Wang, X.; Li, P.; Dangott, L. J.; Hu, W.; Wu, G., 2008: Intrauterine growth restriction affects the proteomes of the small intestine, liver, and skeletal muscle in newborn pigs. The Journal of Nutrition 138, 60-66.

Wu, G.; Bazer, F. W.; Wallace, J. M.; Spencer, T. E., 2006: Board-invited review: intrauterine growth retardation: implications for the animal sciences. Journal of Animal Science 84, 2316.

Yanusova, R. D.; Neville, T. L.; Vonnahme, K. A.; Hammer, C. J.; Reed, J. J.; Taylor, J. B.; Redmer, D. A.; Reynolds, L. P.; Caton, J. S., 2013: Impacts of maternal selenium supply and nutritional plane on visceral tissues and intestinal biology in 180-day-old offspring in sheep. Journal of Animal Science 91, 2229-2242. 